\title{
Crustal thickness constraints on the geodynamic evolution of the Galapagos Volcanic Province
}

\author{
Valentí Sallarès*, Philippe Charvis \\ Institut de Recherche pour le Développement, Géosciences Azur, Observatoire Océanologique de Villefranche, B.P. 48, \\ 06235 Villefranche-sur-mer, France
}

Received 31 March 2003; received in revised form 3 July 2003; accepted 3 July 2003

\begin{abstract}
We developed a simple quantitative framework based on crustal thickness estimations along the Carnegie, Cocos and Malpelo ridges, to place first-order constraints on the tectonic evolution of the Galapagos Volcanic Province and on the along-axis intensity of the Galapagos melt anomaly during the last $20 \mathrm{~m}$.y. Our results suggest that the CocosNazca spreading centre has migrated northwards at $26 \pm 4 \mathrm{~km} / \mathrm{m} . \mathrm{y}$. with respect to the Galapagos hotspot (GHS) during this period of time. At $\sim 20$ m.y., the GHS was approximately ridge-centered, and thus the along-axis intensity of the melt anomaly at this time was the maximum. At $\sim 11.5 \mathrm{~m}$.y. the hotspot was located $106 \pm 27 \mathrm{~km}$ north of the spreading center, and the along-axis intensity of the melt anomaly was $0.54 \pm 0.04$ of that estimated at $20 \mathrm{Ma}$. At present day it is located at $\sim 190 \mathrm{~km}$ south of the spreading center and the along-axis intensity is only $0.19 \pm 0.03$ of that estimated at $20 \mathrm{Ma}$. These results are used to reconstruct the relative position between the GHS and the CocosNazca Spreading Center. The spreading center passed over the GHS for the last time at 7.4 $\pm 1.3 \mathrm{Ma}$. The Panama fracture zone was initiated at $8.9 \pm 1.6 \mathrm{Ma}$, leading to the separation between the Cocos and Malpelo ridges. The present configuration of the Galapagos Volcanic Province and the plate velocities are consistent with symmetric spreading with a mean full spreading rate of $\sim 60 \mathrm{~km} / \mathrm{m}$.y. along the CNSC during the last 20 m.y. A melt flux for excess crustal production of $9.4 \pm 5.1 \mathrm{~m}^{3} / \mathrm{s}$ is obtained for the Galapagos melt anomaly at $20 \mathrm{Ma}$, implying that the maximum potential intensity of the Galapagos plume is similar to that of the Icelandic plume and twice smaller than the Hawaiian one.
\end{abstract}

(C) 2003 Elsevier B.V. All rights reserved.

Keywords: hotspot-ridge interaction; ridge migration; melt flux; excess crustal production

\section{Introduction}

Large igneous provinces, oceanic plateaus, vol-

\footnotetext{
* Corresponding author. Tel.: +33-493763749; Fax: +33-493763766.

E-mail addresses: valenti.sallares@obs-vlfr.fr (V. Sallarès), philippe.charvis@obs-vlfr.fr (P. Charvis).
}

canic ridges, and seamount chains, are segments of thickened oceanic crust originated in regions showing increased melt production within the mantle source (e.g. [1]). The excess of melting has been typically associated to the presence of thermal anomalies induced by hot plumes rising from the deep mantle [2-4]. Alternatively, recent geophysical and geochemical studies seem to indicate that, in some cases, the effect of other pa- 
rameters such as active upwelling [5,6] or mantlesource compositional heterogeneities (e.g. [7]) can be even more significant than mantle temperatures to account for the excess of melting. The existence of these anomalous regions is reflected by broad swells showing striking topography and gravity anomalies (e.g. [8,9]), which are supported by a combination of crustal thickening (e.g. [10]) and sub-lithospheric mantle density anomalies $[9,11-$ 14].

It is widely accepted that normal oceanic crust (6-7 km thick and MORB-like composition) is generated by decompression melting of normal temperature $\left(\sim 1350^{\circ} \mathrm{C}\right)$ pyrolitic mantle, welling up beneath diverging plates at spreading centers (Fig. 1a) [15]. Higher mantle temperatures (i.e. a thermal anomaly), or a more fertile mantle source (i.e. a geochemical anomaly), may enhance mantle melting beneath the spreading center, generating, in turn, a thicker igneous crust (Fig. 1b) (e.g. [1618]). When the melt anomaly is located at midplate, far away from spreading centers, the excess of melting is likely to thicken the crust mainly by crustal underplating [19-23]. In this case, the total melt production is limited by the presence of a mechanical boundary (i.e. a cold lithospheric lid) restricting the minimum depth at which melt can be generated (Fig. 1c) (e.g. $[18,24])$. Between these two end-member cases, there is a range of intermediate possibilities in which the melt anomaly is located at increasing distances from the spreading center. In these cases, part of the hotspot-related melt feeds the spreading center (Fig. 1c), and spreads laterally along the ridge axis [25-27], while the other part is underplated beneath, or injected in, the pre-existing crust (e.g. [28]). Different geochemical and geophysical observations indicate that plumes can interact with oceanic ridges up to distances of $\sim 1400 \mathrm{~km}$ [27-30], generating along-axis geophysical anomalies of widths exceeding $2000 \mathrm{~km}$ (e.g. [31]).

The Galapagos Volcanic Province (GVP) constitutes an excellent example to investigate hotspot-ridge interactions. It is constituted by several ridges showing thickened oceanic crust, which likely resulted from the interaction between the Galapagos hotspot (GHS) and the Cocos-Nazca spreading center (CNSC) during the last $\sim 20$
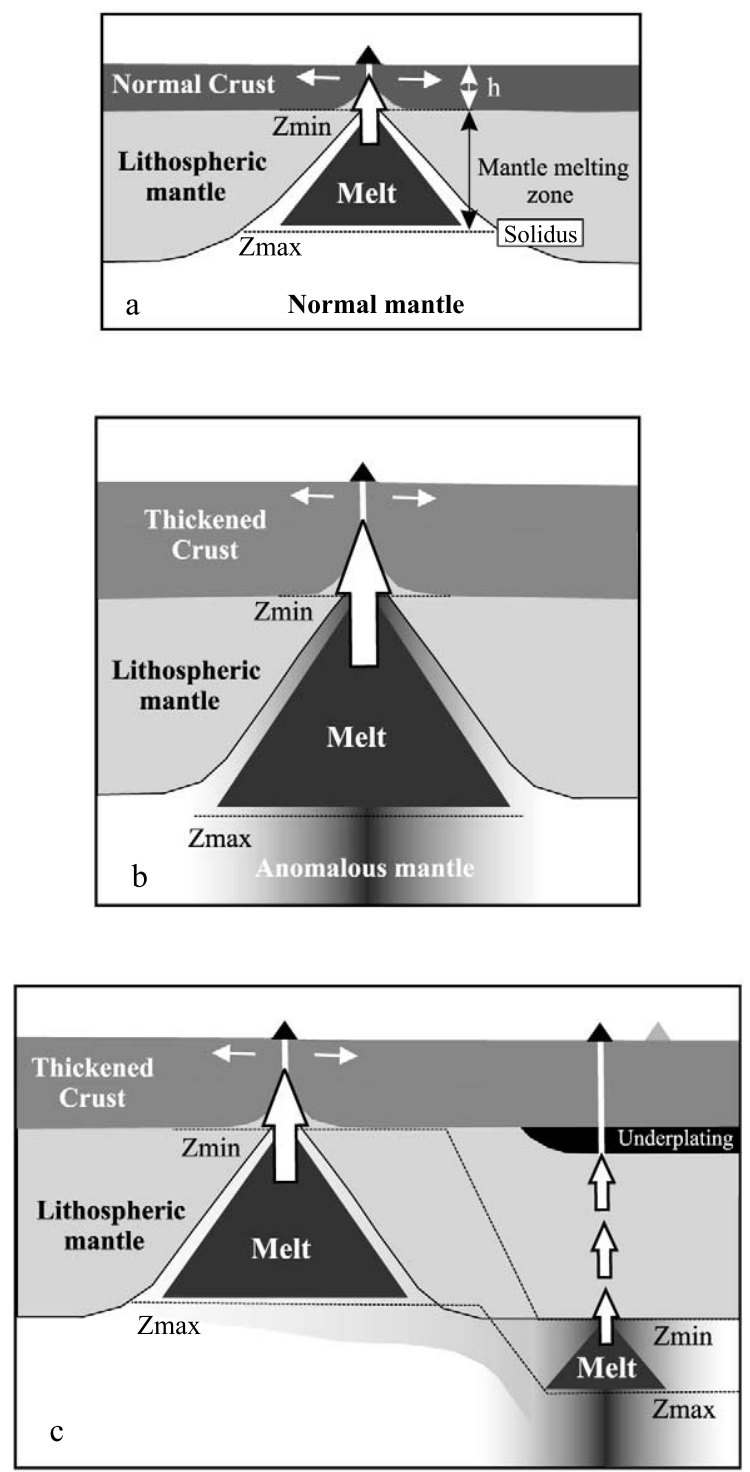

Fig. 1. Sketch summarizing melting processes for crustal generation considering three different situations. (a) Normal spreading center, (b) ridge-centered melt anomaly, (c) offridge melt anomaly. $Z_{\min }$ and $Z_{\max }$ indicate the minimum and maximum depth of melting, which depend primarily on the temperature and composition of the mantle source.

m.y. (Fig. 2). Two of the ridges, Cocos and Carnegie, are interpreted to be the tracks of the GHS over the north-eastward trending Cocos plate and the eastward trending Nazca plate, respectively. These ridges show significant along-strike topographic variations from the currently active 
CNSC to the subduction zones, which seem to be related to temporal variations in the relative hotspot-ridge location [32-35]. However, quantitative comprehensive analysis of the GHS-CNSC relative motion is lacking to date.

The global tectonic evolution of the GVP is relatively well constrained from plate reconstruction based on magnetic and bathymetric data [32,33,36,37], and from recent Global Positioning System (GPS) measurements of the present-day motion of Cocos, Nazca, and South America plates [38-40]. In addition, several seismic experiments were carried out recently in the GVP. These studies have given accurate information on the crustal thickness along the CNSC and at different parts of the hotspot-related volcanic ridges. First, during the PAGANINI-1999 cruise (R/V Sonne, [41]) three wide-angle profiles were acquired across the Cocos and Malpelo ridges [42,43]. Second, the PRIME-2000 cruise (R/V Maurice Ewing) provided a number of wide-angle and multichannel seismic data along the present-day axis of the CNSC [44] and the Galapagos platform [45]. Third, during the SALIERI-2001 cruise (R/V Sonne, [46]) two wide-angle profiles were acquired across the Carnegie Ridge [47] (Fig. 2).

In the present work, we have developed a simple quantitative framework to place first-order constraints on the relative motion of the GHS and the CNSC based on crustal thicknesses of the main volcanic features computed from available seismic data. First, we describe the method used to derive the along-axis intensity of the melt anomaly from crustal thickness estimations. Second, we estimate the relative hotspot-ridge location at different periods of time based on the calculations of the along-axis intensity of the melt anomaly. Third, we estimate the volumetric melt flux of the GHS and we compare the results with that obtained for the Hawaiian and Icelandic hotspots. Finally, we show a tectonic reconstruction of the GVP for the last 20 m.y. which summarizes all the results.

\section{Tectonic setting}

The first consistent model of the tectonic evo- lution of the GVP was established by Hey [32] and Lonsdale and Klitgord [33] based on magnetic and bathymetric data. This model suggests that major plate reorganization occurred in the region at $\sim 23 \mathrm{Ma}$, breaking the ancient Farallon plate along a pre-existing ENE trending PacificFarallon fracture zone. Subsequently, oceanic spreading initiated along the CNSC originating the Cocos and Nazca plates. The interaction between the GHS and the CNSC originated the north-eastward trending Cocos Ridge and the eastward trending Carnegie Ridge, which outline the motion of the Cocos and Nazca plates relative to the GHS, respectively $[48,49]$. Based on the analysis of magnetic anomalies and dredge samples, a three stage development of the CNSC has been proposed, suggesting that the orientation of the spreading center varied from the original ENE ( 23-19.5 Ma), to $\mathrm{N} 75^{\circ} \mathrm{E}(19.5-14.5 \mathrm{Ma})$, and finally to the present E-W orientation (14.5 Ma) [35]. These data also evidenced that the history of rift propagation along the CNSC is complex, being characterized by series of major southward ridge jumps between $\sim 20$ and $14.5 \mathrm{Ma}$ which kept the CNSC not far from the GHS during this period of time. The activation of the main tectonic event along the CNSC, the Panama fracture zone (PFZ), occurred between $13 \mathrm{Ma}$ [32] and 8-11 Ma [33] (Fig. 2). This event caused the end of seafloor spreading east of the PFZ, whereas it continued west of it until present day $[32,48]$. The Malpelo Ridge is thought to be the former continuation of the Cocos Ridge, drifted away by the dextral strike-slip motion along the PFZ [33].

Recent GPS measurements indicate that the Cocos plate is moving at a rate of $\sim 83 \mathrm{~km} / \mathrm{m}$.y. with a trend of $\sim \mathrm{N} 41^{\circ} \mathrm{E}$, and that the Nazca plate subducts almost perpendicularly beneath South America at $\sim 58 \mathrm{~km} / \mathrm{m}$.y. with respect to the stable South American craton $[38,40]$. The age of the Cocos Ridge subducting at the trench is $\geq 14.5 \mathrm{~m}$.y. based on radiometric data [50], and the age of Carnegie Ridge at the trench and the conjugate Malpelo Ridge is estimated to be $\sim 20$ m.y. from reconstruction of magnetic anomalies [32].

If we assume that the GHS is currently centered beneath the most active island of the Galapagos 

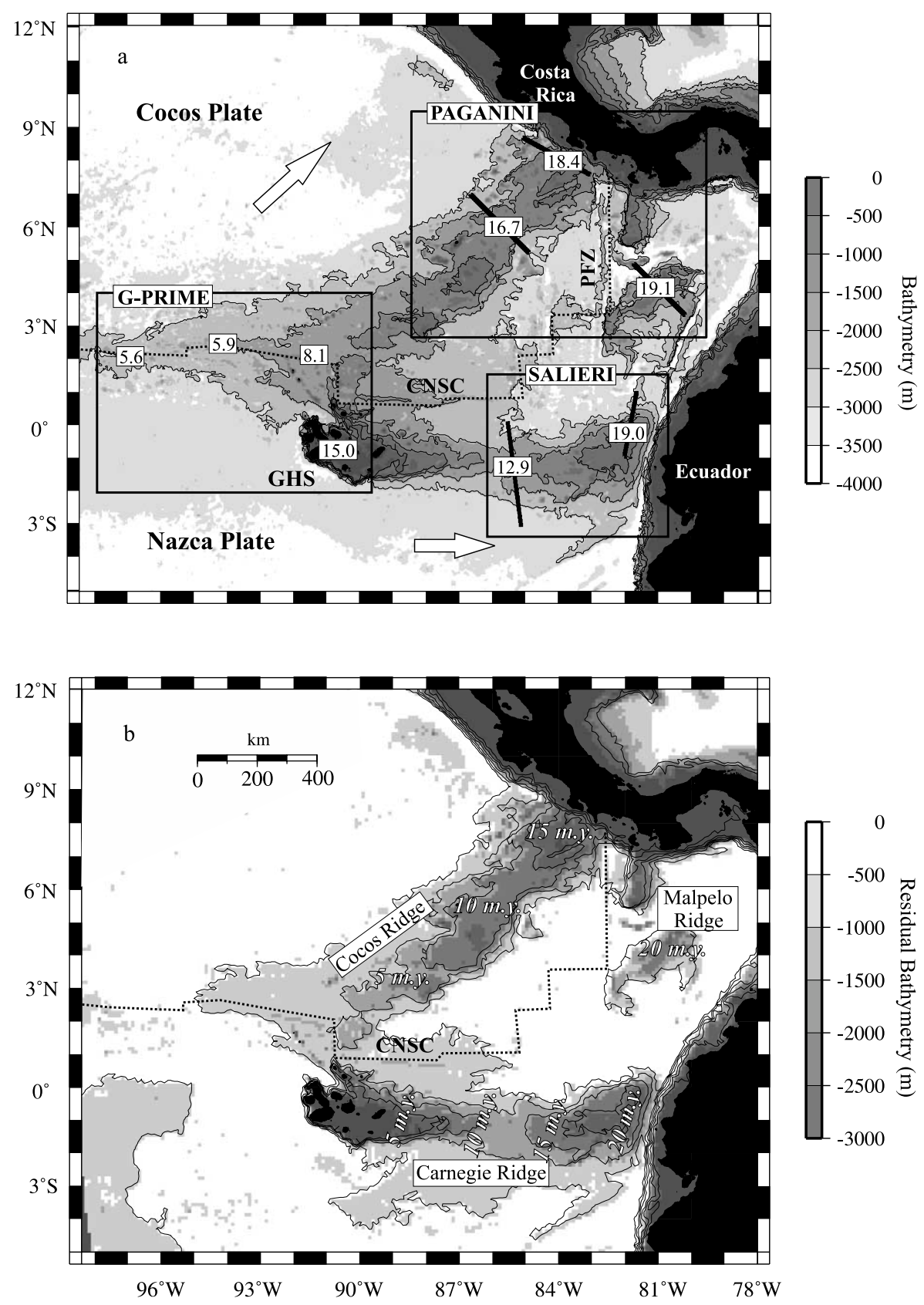

Fig. 2. (a) Bathymetric map of the GVP showing the main tectonic and geologic features of the area. Large arrows display plate motions relative to the stable South American craton [40]. Black lines show location of all the wide-angle seismic profiles used in this work, and numbers indicate the maximum crustal thickness obtained along these profiles [43-45,47]. Boxes outline the different seismic experiments recently performed in the area (PAGANINI-1999, G-PRIME-2000, SALIERI-2001). CNSC: Cocos-Nazca spreading center, GHS: Galapagos hotspot, PFZ: Panama fracture zone. (b) Residual bathymetry of the GVP. It is the bathymetry derived from the seafloor age [58], based on the plate cooling model of Parsons and Sclater [59] for oceanic crust younger than 70 m.y. $\left(d=2500+350 t^{1 / 2}\right)$, minus the bathymetry shown in Fig. 2a. Note that in this case depth anomalies mainly reflect crustal thickness variations. Numbers show crustal ages of oceanic plates at $5 \mathrm{Ma}$ interval [58]. 
Archipelago (Isabela), the distance between the CNSC and the hotspot is $\sim 190 \mathrm{~km}$. The full spreading rate at $90^{\circ} \mathrm{W}$ is $60 \pm 4 \mathrm{~km} / \mathrm{m} . \mathrm{y}$., using the global plate model NUVEL-1A [51], or $66 \pm 4 \mathrm{~km} / \mathrm{m} . \mathrm{y}$., from GPS measurements [38]. Magnetic anomalies suggest that seafloor spreading along the CNSC has been roughly symmetric though slightly variable during the last 20 m.y. [36,35]. The CNSC has moved toward the north with respect to the hotspot at a velocity of $\sim 27$ $\mathrm{km} / \mathrm{m} . \mathrm{y}$. [52], similar to the half-spreading rate, which could explain the approximate E-W trend of the Carnegie Ridge. The migration of the CNSC, combined with prominent ridge jumps and temporal variations in the full spreading rate, have resulted in temporal variations in the relative location of the hotspot with respect to the spreading center. Although the details of the relative motion are not fully understood, bathymetric and magnetic data seem to indicate that between $\sim 20 \mathrm{Ma}$ and $15 \mathrm{Ma}$ the hotspot was approximately ridge-centered, then at $\sim 14.5 \mathrm{Ma}$ a southward ridge jump placed the hotspot beneath the Cocos plate [35]. Eventually, at 7-9 $\mathrm{Ma}$, the CNSC passed over the GHS, and from this moment to present day the hotspot has been located beneath the Nazca plate [36].

\section{Volumetric melt flux provided by a melt anomaly}

If we assume that all mantle melts feeding a ridge are emplaced as seismically observable igneous crust (e.g. [15]), the excess of crustal thickness along the ridge axis (compared to normal oceanic crust) can be used to estimate the additional melt flux provided by a melt anomaly $[29,44]$. This value is called the volumetric melt flux for extra crustal production, and can be taken as a measure of the along-axis intensity of the melt anomaly. The temporal variations of along-axis crustal thickness may be in turn interpreted to be the result of variations in the relative distance between the melt anomaly and the spreading center. Basic assumptions made with this inference include: (1) the temporal variations in the maximum potential intensity of the melt anomaly are negligible, and (2) the along-axis width of plume material flow, $W$, and the full spreading rate, $U$, are constant over time. The validity of these two assumptions is discussed in the next section.

In the following sections, we first describe and then apply a method based on this idea to estimate the first-order temporal variations in the intensity of the Galapagos melt anomaly along the axis of the CNSC, which is subsequently used to approximate the relative location of the GHS with respect to the spreading center at different periods of time. All those calculations are based on several crustal thickness estimations at the GVP.

\subsection{Data set}

The data set is constituted by a number of crustal thickness estimations along eight wide-angle seismic profiles and some multichannel seismic lines acquired along the CNSC and across the volcanic ridges of the GVP (Fig. 2).

Three of the wide-angle profiles and all the MCS data were acquired along the present-day axis of the CNSC (between $97^{\circ} \mathrm{W}$ and $91^{\circ} 20^{\prime} \mathrm{W}$ ) in 2000, during the G-PRIME experiment. Based on part of these data, Canales et al. [44] constrained the crustal thickness variations along the western CNSC. A maximum crustal thickness of $8.1 \pm 0.2 \mathrm{~km}$ is obtained at $91^{\circ} 25^{\prime} \mathrm{W}, \sim 290 \mathrm{~km}$ north of the inferred location of the GHS. A minimum crustal thickness of $5.6 \pm 0.2 \mathrm{~km}$ is obtained at $\sim 97^{\circ} \mathrm{W}, \sim 700 \mathrm{~km}$ away from the point where the crust is the thickest. At roughly mid-distance, $\sim 94^{\circ} \mathrm{W}$, the crust is only $5 \%$ thicker with $5.9 \pm 0.3 \mathrm{~km}$ (Fig. 2). Thus, the rate of crustal thickening is around five times higher east of $94^{\circ} \mathrm{W}$ than west of it, suggesting that the lateral extent of the along-axis migration of GHS melts is confined primarily to within $\sim 350 \mathrm{~km}$ from the point where the crust is thickest [44]. Therefore, the crust generated at $97^{\circ} \mathrm{W}$ is considered to be outside of the zone of hotspot influence, and can be taken as a reference for normal CNSC oceanic crust.

Two wide-angle profiles were acquired across the Cocos Ridge at the subduction zone and at $\sim 6^{\circ} \mathrm{N}$, and another one across the Malpelo Ridge, during the PAGANINI-1999 experiment. 
Other profiles were collected across the Carnegie Ridge immediately east of the trench and at $\sim 85^{\circ} \mathrm{W}$, during the SALIERI-2001 experiment. These two profiles are located approximately at the conjugate segments of the Malpelo profile and the southern Cocos profile, respectively. Seismic velocity models with the Moho geometry along those five profiles were obtained using a joint refraction and reflection travel time inversion method [5]. Uncertainties of the model parameters (i.e. seismic velocities and Moho depth) were estimated by performing a Monte Carlo-type analysis. Results indicate that maximum crustal thickness is $12.9 \pm 0.3 \mathrm{~km}$ in western Carnegie, $19.0 \pm 0.4 \mathrm{~km}$ in eastern Carnegie [43], $16.7 \pm 0.3$ in southern Cocos, $18.4 \pm 0.5 \mathrm{~km}$ in northern Cocos, and $19.1 \pm 0.3 \mathrm{~km}$ in Malpelo [47] (Fig. 2).

The age of the seafloor at the location of the different profiles can be inferred from plate velocities derived from GPS measurements [40], and magnetic data [35]. For Malpelo Ridge and its conjugate eastern Carnegie Ridge, an age of $20.0 \pm 0.5$ m.y. is obtained. For southern Cocos Ridge and its conjugate western Carnegie Ridge, the age is $\sim 11.5 \pm 0.5$ m.y., whereas for the northern Cocos profile it is $\sim 15.5 \pm 0.5$ m.y. [35]. The later estimation is consistent with that obtained from ${ }^{40} \mathrm{Ar} /{ }^{39} \mathrm{Ar}$ dating of volcanic samples offshore southern Costa Rica, which indicates that the age of the segment of the Cocos plate currently subducting beneath Middle America just west of the Cocos Ridge is $\sim 14.5$ m.y. [50].

The comparison of isochronous crustal thickness differences at both sides of the CNSC allows inferring the relative location of the GHS with respect to the spreading center at the different periods of time. At $\sim 11.5 \mathrm{Ma}$ a thicker crust is obtained north of the CNSC than south of it, indicating that the GHS was probably located beneath the Cocos plate, north of the spreading center. At $\sim 20 \mathrm{Ma}$, the crustal thickness is almost the same at both sides of the CNSC. This suggests that the GHS was approximately ridgecentered at this time, thus providing a useful constraint on the maximum potential intensity of the Galapagos melt anomaly. At $\sim 15.5 \mathrm{Ma}$, the ridge's crust north of CNSC is slightly thinner than that generated at $\sim 20 \mathrm{Ma}$, but significantly thicker than that generated at $\sim 11.5 \mathrm{Ma}$ (Fig. 2), suggesting that at $\sim 15.5 \mathrm{Ma}$ the GHS was quite closer to the spreading center than at $\sim 11.5 \mathrm{Ma}$.

None of these profiles is parallel to the paleoaxis of the CNSC. However, the excess of crustal thickness along the thinnest of two conjugate segments can be used as a proxy to estimate the along-axis volumetric melt flux provided by the GHS. The thickest of both conjugate segments is thus the result of the along-axis crustal production and additional off-ridge crustal thickening by intra-plate volcanism (Fig. 1c).

\subsection{Method}

The method that we describe here allows calculating the relative distance between a melt anomaly and a spreading center from crustal thickness estimations along the ridge axis. To do that, we first calculate the along-axis volumetric melt flux for extra crustal production, $Q_{\mathrm{v}}$. Second, we determine the maximum along-axis potential intensity of the melt anomaly, $Q_{\mathrm{M}}$, and we estimate its relative intensity at different periods of time. Finally, we link the temporal variations of $Q_{\mathrm{v}}$ with the relative distance of the melt anomaly center and the ridge axis.

$Q_{\mathrm{v}}$ can be calculated from crustal thickness measurements along the axis of a spreading center as follows (e.g. [28]):

$Q_{\mathrm{v}}=U \int_{W}\left(h_{\mathrm{c}}(x)-h\right) \mathrm{d} x$

where $U$ is the full spreading rate, $W$ is the alongaxis width of the overthickened crustal segment, $x$ is along-axis distance, $h_{\mathrm{c}}(x)$ is the crustal thickness measured at $x$, and $h$ represents normal crustal thickness.

A first issue with this inference is that we rarely know the Moho geometry along the axis of a spreading center. As we stated in the previous section, the Moho geometry is well constrained along the present-day axis of the CNSC, but not along the paleo-ridge axis. Nevertheless, the comparison of the conjugate profiles at $\sim 11.5 \mathrm{Ma}$ and $\sim 20 \mathrm{Ma}$ allows to estimate, at least, which was the maximum crustal thickness generated along the ridge axis at both periods of time 
(Fig. 1). Then, we can approximate in first order the along-axis Moho geometry, $h_{\mathrm{c}}(x)$, with a function decaying linearly from $H$ at $x=0$, to $h$ at $x= \pm W / 2$. In this case Eq. 1 is reduced to:

$Q_{\mathrm{v}}=\frac{(H-h) U W}{2}$

where $H$ is the maximum crustal thickness along the ridge axis at a given period of time.

In a second approach, we assume that the temporal variations of $Q_{\mathrm{v}}$ are primarily the result of variations in the distance between the melt anomaly and the spreading center. This hypothesis implies that the temporal variations of the maximum potential intensity of the melt anomaly are negligible. We assumed that to perform our analysis, because it is the simplest hypothesis and there is not any evidence against it. The comparison of our results with those obtained in other works using independent data and methods will allow to see if the assumption is plausible.

Therefore, if the temporal variations of $Q_{\mathrm{v}}$ are the result of the hotspot-ridge distance, $Q_{\mathrm{v}}$ must be maximum when the melt anomaly is ridge-centered, and asymptotic to zero for increasing hotspot-ridge distance. This tendency can be represented by the following function:

$Q_{v}=Q_{M} \exp (-\alpha y)$

where $Q_{\mathrm{M}}$ represents the maximum potential volumetric melt flux (i.e. for a ridge-centered anomaly), $y$ is the relative hotspot-ridge distance, and $\alpha$ is a factor which determines the shape of the function. This function does not represent a rigorously based physical model but it is only an assumed idealization. Then, defining:

$\chi=\frac{Q_{\mathrm{v}}}{Q_{\mathrm{M}}}$

and comparing this value for two different profiles, we obtain from Eq. 3:

$y \log \chi_{0}=y_{0} \log \chi$

where $\chi\left(\chi_{0}\right)$ represents the relative intensity of the along-axis melt anomaly when it is located at $y$ $\left(y_{0}\right)$ from the spreading center.

A second issue with this approach concerns the estimate of $U$ and $W$ in order to determine $Q_{\mathrm{v}}$ from Eq. 2. In a previous work based on the analysis of along-isochron bathymetric $(\Delta R B)$ and gravity $(\triangle \mathrm{MBA})$ anomalies along the presentand paleo-ridge axis for a number of hotspotridge systems, Ito and Lin [34] showed that whereas the amplitudes of $\triangle \mathrm{RB}$ and $\triangle \mathrm{MBA}$ are functions of ridge-hotspot distance, $W$ depends primarily on $U$ at the time of crustal accretion, in agreement with previous notions of along-axis plume material flow [26,28]. For the GHS-CNSC system, it has been shown that the along-isochron width of $\Delta \mathrm{RB}$ has been roughly constant between 7.7 Ma and 2.5 Ma (1250-1300 km) [29], despite the significant variations on the relative hotspotridge distance $(\sim 0-100 \mathrm{~km})$. In addition, a recent tectonic reconstruction of the GVP based on magnetic data [35] suggests that the spreading rate along the CNSC east of $90^{\circ} \mathrm{W}$ has been nearly symmetric and uniform $(U \sim 60-70 \mathrm{~km} / \mathrm{m} . \mathrm{y}$.) between $\sim 19.5$ m.y. and present day. Therefore, we assume, as a crude approximation, that both $U$ and $W$ did not vary significantly during the last $\sim 20$ m.y. Then, substituting Eq. 2 into Eq. 4 we obtain:

$\chi=\frac{H-h}{H_{\mathrm{M}}-h}$

In conclusion, if we know the maximum potential crustal thickness that can be generated by a melt anomaly, $H_{\mathrm{M}}$, and the hotspot-ridge distance, $y_{0}$, and maximum along-axis crustal thickness, $H_{0}$, at a given period of time, Eqs. 5 and 6 provide an easy way to place first-order constraints on the relative intensity of the along-axis melt anomaly, $\chi$, and thus on the hotspot-ridge distance, $y$, at any other time at which we know the maximum along-axis crustal thickness, $H$.

\section{Results}

In the following sections, we first estimate the relative intensity of the along-axis melt anomaly at present day, at $\sim 11.5 \mathrm{Ma}$, and at $\sim 15.5 \mathrm{Ma}$ with respect to its maximum potential intensity, which is obtained at $\sim 20 \mathrm{Ma}$. The results are used to infer the relative hotspot distance at these periods of time, and thus the relative motion of 
the CNSC with respect to the GHS during the last 20 m.y. The CNSC migration rate is then used to determine the age of the activation of the PFZ and the time at which the CNSC passed over the GHS from south to north. Finally, we estimate the volumetric melt flux for excess crustal production at the GHS and we compare the results with those obtained at the Hawaiian and Icelandic plumes.

We have also performed a formal error propagation analysis using the expression of the total differential (Eq. 7), in order to estimate the order of uncertainty of the results:

$\Delta z=\sum_{i=1}^{N}\left|\frac{\partial f}{\partial x_{i}}\right| \Delta x_{i}$

where $z=f\left(x_{\mathrm{i}}\right)$ is a function of the independent variables $x_{\mathrm{i}}(i=1, \ldots, N)$, and $\Delta x_{\mathrm{i}}$ is the uncertainty of these variables.

Since many steps of our model are not general but strongly assumption-dependent, this uncertainty does not represent the real error of the results, but only that associated to the propagation of the errors of the basic variables, assuming a given functional relationship.

\subsection{Relative intensity of the melt anomaly and hotspot-ridge distance}

As we stated above, the similar crustal thickness obtained along the Malpelo and eastern Carnegie Ridge indicate that at $\sim 20 \mathrm{Ma}$ the GHS was approximately ridge-centered. Then, we can assert that at this time the intensity of the alongaxis melt anomaly was the maximum $(\chi \sim 1)$. By comparing this crustal thickness with that estimated away from the zone of hotspot influence (Fig. 2) we obtain that the maximum potential along-axis crustal thickening $(\Delta H)$ associated with the presence of the GHS is $13.4 \pm 0.5 \mathrm{~km}$. Along the present-day axis, $\Delta H$ is $2.5 \pm 0.4 \mathrm{~km}$, and from Eq. 6 we obtain $\chi=0.19 \pm 0.03$. At $\sim 11.5 \mathrm{Ma}$, we obtain $\Delta H=7.3 \pm 0.5 \mathrm{~km}$ and $\chi=0.54 \pm 0.04$. The lack of crustal thickness information at the conjugate segment of the northern Cocos profile (Fig. 2) makes it impossible to infer the relative hotspot-ridge location at $\sim 15.5 \mathrm{Ma}$. However, if we assume that the GHS was located slightly south of the CNSC, we would obtain $\Delta H=12.8 \pm 0.7 \mathrm{~km}$ and $\chi=0.95 \pm 0.04$.

The relative distance between the hotspot and the ridge at the different periods of time can be then estimated from Eq. 5 using as reference the distance from the GHS to the point of the CNSC where the thickest crust is generated at present day, $y_{0}=290 \pm 10 \mathrm{~km}$ (a in Fig. 3). The relative distance was obviously $y \sim 0$ at $\sim 20$ Ma. At $\sim 11.5 \mathrm{Ma}$ we obtain $y=106 \pm 27 \mathrm{~km}$, and at $\sim 15.5 \mathrm{Ma}$ it would be only $y=9 \pm 9 \mathrm{~km}$.

\subsection{Regional implications of ridge migration}

The N-S component of the mean relative velocity between the GHS and the CNSC, $V_{\mathrm{NS}}$, can be estimated by comparing their relative distances at present day $(190 \pm 10 \mathrm{~km}, \mathrm{~b}$ in Fig. 3), and at $\sim 11.5 \mathrm{Ma}$. From the results described in the previous section we obtain $V_{\mathrm{NS}}=26 \pm 4 \mathrm{~km} / \mathrm{m}$.y. (Fig. 3). Assuming that the GHS remains fixed in the deep mantle reference frame, this result denotes the northward migration of the CNSC with respect to the GHS. This is in good agreement with the $\sim 27 \mathrm{~km} / \mathrm{m}$.y. migration rate derived from the NUVEL-1 global plate motion model in the hotspot reference frame [52].

The GVP is moving eastwards at a mean rate, $V_{\mathrm{EW}}=58 \pm 2 \mathrm{~km} / \mathrm{m} . \mathrm{y}$, measured from GPS data [40] (Fig. 3). This motion is essentially the result of the E-W seafloor spreading along the East Pacific Rise. Using $V_{\mathrm{NS}}$ and $V_{\mathrm{EW}}$, we have inferred the location of the GHS in the CNSC reference frame at $\sim 11.5 \mathrm{Ma}, \sim 15.5 \mathrm{Ma}$, and $\sim 20 \mathrm{Ma}$, in order to compare the results with those predicted by our model (Fig. 3). At $15.5 \mathrm{Ma}$, the GHS would be $\sim 30 \mathrm{~km}$ south of the CNSC; and at $20 \mathrm{Ma}$, it would be approximately ridge-centered (assuming that the CNSC was continuous before the opening of the PFZ). The result at $20 \mathrm{Ma}$ is therefore consistent with the predictions of our hotspot-ridge interaction model. At $15.5 \mathrm{Ma}$ the model predicts that the GHS would have to be $\sim 20 \mathrm{~km}$ northward from the inferred location. It is not possible, however, to say whether this discrepancy is real or not, because the inferred location is well within the limits of uncertainty of the model. 


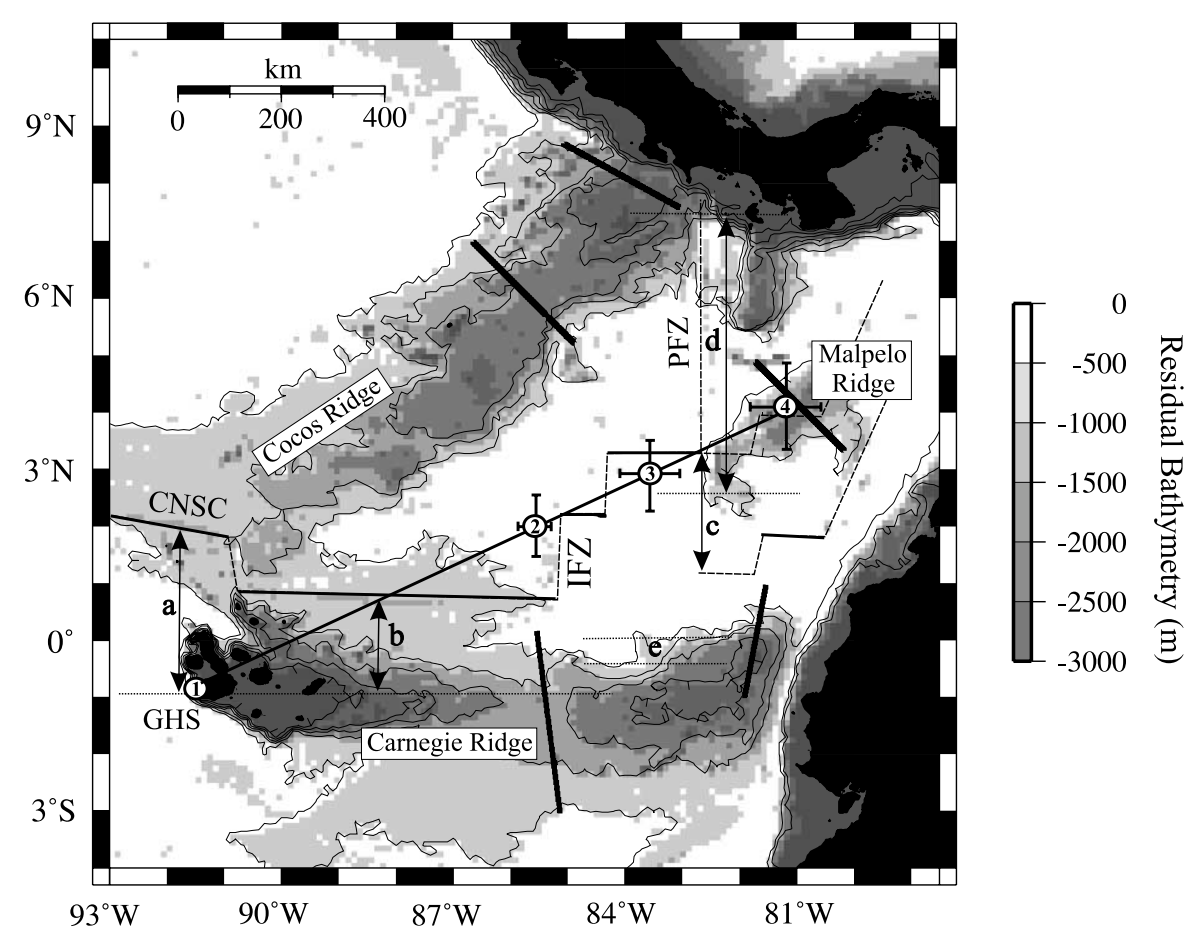

Fig. 3. Residual bathymetry map of the GVP. White disks with error bars indicate the location of the Galapagos melt anomaly center in the CNSC reference frame, as inferred from the results of this work: (1) present day, (2) $11.5 \pm 0.5 \mathrm{Ma}$, (3) $15.5 \pm 0.5$ Ma, (4) $20.0 \pm 0.5 \mathrm{Ma}$. The solid line indicates the inferred trajectory of the GHS in the CNSC reference frame. The thin line shows the current location of the CNSC. The active segment is located west from $83^{\circ} \mathrm{W}$, and the fossil segment east of $83^{\circ} \mathrm{W}$. Dashed line displays the inferred location of the CNSC before the opening of the PFZ. Relative distances: (a) GHS-nearest along-axis wide-angle seismic profile, (b) GHS-CNSC, (c) lateral step between active and fossil segments of the CNSC, (d) separation between Cocos and Malpelo ridges, (e) scarp of the Carnegie Ridge. Full explanation of their respective significance is provided in the text. CNSC: Cocos-Nazca spreading center; IFZ: Inca fracture zone; PFZ: Panama fracture zone.

Using the CNSC migration rate, $V_{\mathrm{NS}}$, and the present-day GHS-CNSC distance (b in Fig. 3), we can infer that the spreading center passed over the GHS at $7.4 \pm 1.3 \mathrm{Ma}$, which is in agreement with the 7-9 m.y. estimated by Wilson and Hey [36] from the interpretation of magnetic data. In addition, it is possible to constrain the time of opening of the PFZ, $t_{\mathrm{PFZ}}$, in view of the $230 \pm 10$ $\mathrm{km}$ lateral step between the fossil segment of the CNSC east of the PFZ and the western (active) segment (c in Fig. 3). West of the PFZ, the Cocos plate is subducting beneath Middle America, but east of PFZ the northward subduction is currently blocked (Fig. 3). Assuming that $c$ is the result of the northward migration of the CNSC after the opening of the PFZ, which did not occur east of the PFZ, we obtain $t_{\mathrm{PFZ}}=8.9 \pm 1.6 \mathrm{Ma}$. Previous estimations of $t_{\mathrm{PFZ}}$ range between $\sim 13 \mathrm{Ma}$ [32] and 8-11 Ma [33]. Our result is thus more in agreement with the later value.

It is widely accepted that the Malpelo Ridge is a former continuation of the Cocos Ridge, drifted southward along the dextral strike-slip PFZ. Consequently, the lateral $\mathrm{N}-\mathrm{S}$ shift of $510 \pm 10 \mathrm{~km}$ between Cocos and Malpelo ridges ( $d$ in Fig. 3) must be the result of the northward CNSC migration, $V_{\mathrm{NS}}$, in addition to the mean northward half-spreading rate, $U_{\mathrm{N}}$, along the CNSC, after the opening of the PFZ. Taking the values obtained above, we obtain $U_{\mathrm{N}}=d / t_{\mathrm{PFZ}}-V_{\mathrm{NS}}=31 \pm$ $13 \mathrm{~km} / \mathrm{m} . \mathrm{y}$. (Fig. 3).

South of the CNSC, the differential motion of the oceanic basins west and east of the PFZ is much less marked than north of it, because in this part the northward migration of the CNSC is mostly compensated by the southward seafloor 
spreading along the CNSC, $U_{\mathrm{s}}$. The only feature that is observed in the Nazca plate is a lateral step of $50 \pm 10 \mathrm{~km}$ in the northern flank of the Carnegie Ridge (e in Fig. 3). Considering that this step is the result of the differential motion we obtain $U_{\mathrm{s}}=e / t_{\mathrm{PFZ}}+V_{\mathrm{NS}}=31 \pm 6 \mathrm{~km} / \mathrm{m} . \mathrm{y}$. (Fig. 3 ).

Therefore, we conclude from our basic evaluation that roughly symmetric spreading with a mean full spreading rate of $62 \pm 19 \mathrm{~km} / \mathrm{m} . \mathrm{y}$. has taken place along the CNSC during at least the last $\sim 10$ m.y. (between $\sim 91^{\circ} \mathrm{W}$ and the PFZ). As stated above, the global plate motion model NUVEL-1A predicts a full spreading rate varying from $58 \pm 3 \mathrm{~km} / \mathrm{m}$.y. at $90^{\circ} \mathrm{W}$ to $63 \pm 4 \mathrm{~km} / \mathrm{m}$.y. at $87^{\circ} \mathrm{W}$ [51], whereas a rate of $66 \pm 4 \mathrm{~km} / \mathrm{m}$.y. is obtained from GPS data [38].

The north-eastward motion of the Cocos plate with respect to the stable South American craton must be then the result of the northward component of N-S oceanic spreading along the CNSC, $U_{\mathrm{N}}$, the northward ridge migration, $V_{\mathrm{NS}}$, and the eastward motion of the GVP towards South America, $V_{\mathrm{EW}}$ (Fig. 3). By combining the values that we obtained above, we infer that the Cocos plate has been moving at a mean rate of $79 \pm 14$ $\mathrm{km} / \mathrm{m}$.y. with a mean trend of $\mathrm{N} 44 \pm 11^{\circ} \mathrm{E}$. This is also in agreement with the $\sim 83 \mathrm{~km} / \mathrm{m}$.y. and $\sim \mathrm{N} 41^{\circ} \mathrm{E}$ measured from GPS data [40].

\subsection{Volumetric melt flux for excess crustal production}

The total volumetric melt flux for excess crustal production currently supplied by the GHS, $Q_{\mathrm{T}}$, is the aggregate of excess volume flux at the presentday axis of the CNSC, $Q_{\mathrm{CNSC}}$, and at the Galapagos platform, $Q_{\mathrm{GP}}$ (Fig. 1c). $Q_{\mathrm{CNSC}}$ can be approximated using an estimate of $W(700 \pm 50 \mathrm{~km}$, [44]) and the full spreading rate, $U$, which we obtained in the previous section. Then, from Eq. 2 we obtain $Q_{\mathrm{CNSC}}=1.6 \pm 1.5 \mathrm{~m}^{3} / \mathrm{s}$, in agreement with the $\sim 1.5 \mathrm{~m}^{3} / \mathrm{s}$ determined by Canales et al. [44]. Maximum crustal thickness beneath the Galapagos platform has been reported to be $\sim 15 \mathrm{~km}$ from wide-angle data acquired during the GPRIME experiment (Fig. 2) [45]. Then, we have determined $Q_{\mathrm{GP}}$ from Eq. 2 considering the N-S extent of the overthickened crustal section ob- tained across the western Carnegie Ridge $(325 \pm 25 \mathrm{~km})$ [47], and the E-W motion rate of the Nazca plate, $V_{\mathrm{EW}}$. This gives $Q_{\mathrm{GP}}=2.8 \pm 1.6$ $\mathrm{m}^{3} / \mathrm{s}$, which is near the upper bound of the $0.3-3.0$ $\mathrm{m}^{3} / \mathrm{s}$ previously reported by Ito et al. [29] from the analysis of gravity and topographic anomalies along the Carnegie Ridge between $85^{\circ} \mathrm{W}$ and $92^{\circ} \mathrm{W}$. This means that the total excess volume flux currently supplied by the GHS is $Q_{\mathrm{T}}=4.4 \pm$ $3.1 \mathrm{~m}^{3} / \mathrm{s}$.

At $\sim 20$ Ma, an excess volume flux of $Q_{\mathrm{v}}=9.4 \pm 5.1 \mathrm{~m}^{3} / \mathrm{s}$ is obtained considering the same values of $W$ and $U$ that we used to calculate $Q_{\mathrm{CNSC}}$. This value is more than twice larger than the total excess volume flux estimated at present day, $Q_{\mathrm{T}}$. Assuming that the maximum potential intensity of the Galapagos melt anomaly has remained constant during this period of time, the difference in $Q_{\mathrm{v}}$ must be explained by the presence of a mechanical boundary (i.e. the lithosphere originated at the spreading axis), which restricts the extent of the mantle melting zone and, in turn, the total amount of melt generated beneath the Galapagos platform (e.g. [52]) (Fig. 1c).

We have performed a similar analysis for two end-member examples of purely intra-plate (Hawaii) and ridge-centered (Iceland) plumes, in order to compare the excess volume flux provided by these plumes with those obtained in the GVP at present day (intraplate case) and at $\sim 20 \mathrm{Ma}$ (ridge-centered case). Maximum crustal thickness across the swell of the Hawaiian hotspot near Oahu and Kauai islands is $14-15 \mathrm{~km}$, whereas normal crustal thickness of the Pacific plate is $\sim 7 \mathrm{~km}$. The across-ridge width of the overthickened crustal section is $\sim 400 \pm 25 \mathrm{~km}$ [53]. Based on the model NUVEL-1A, the Pacific plate is moving at approximately $105 \pm 5 \mathrm{~km} / \mathrm{m}$.y. with respect to the Hawaiian hotspot [54]. We thus obtain an excess volume flux, $Q_{\mathrm{H}}=5.0 \pm 3.7 \mathrm{~m}^{3} / \mathrm{s}$ for the Hawaiian hotspot, in agreement with the $\sim 5.1 \mathrm{~m}^{3} / \mathrm{s}$ estimated by Watson and McKenzie [24] from numerical modelling. By comparing this value with that obtained beneath the Galapagos platform, $Q_{\mathrm{GP}}$, we can infer that the Hawaiian melt anomaly is, potentially, almost twice stronger than the Galapagos one, which is consistent with the estimates of Phipps Morgan [52]. In Ice- 

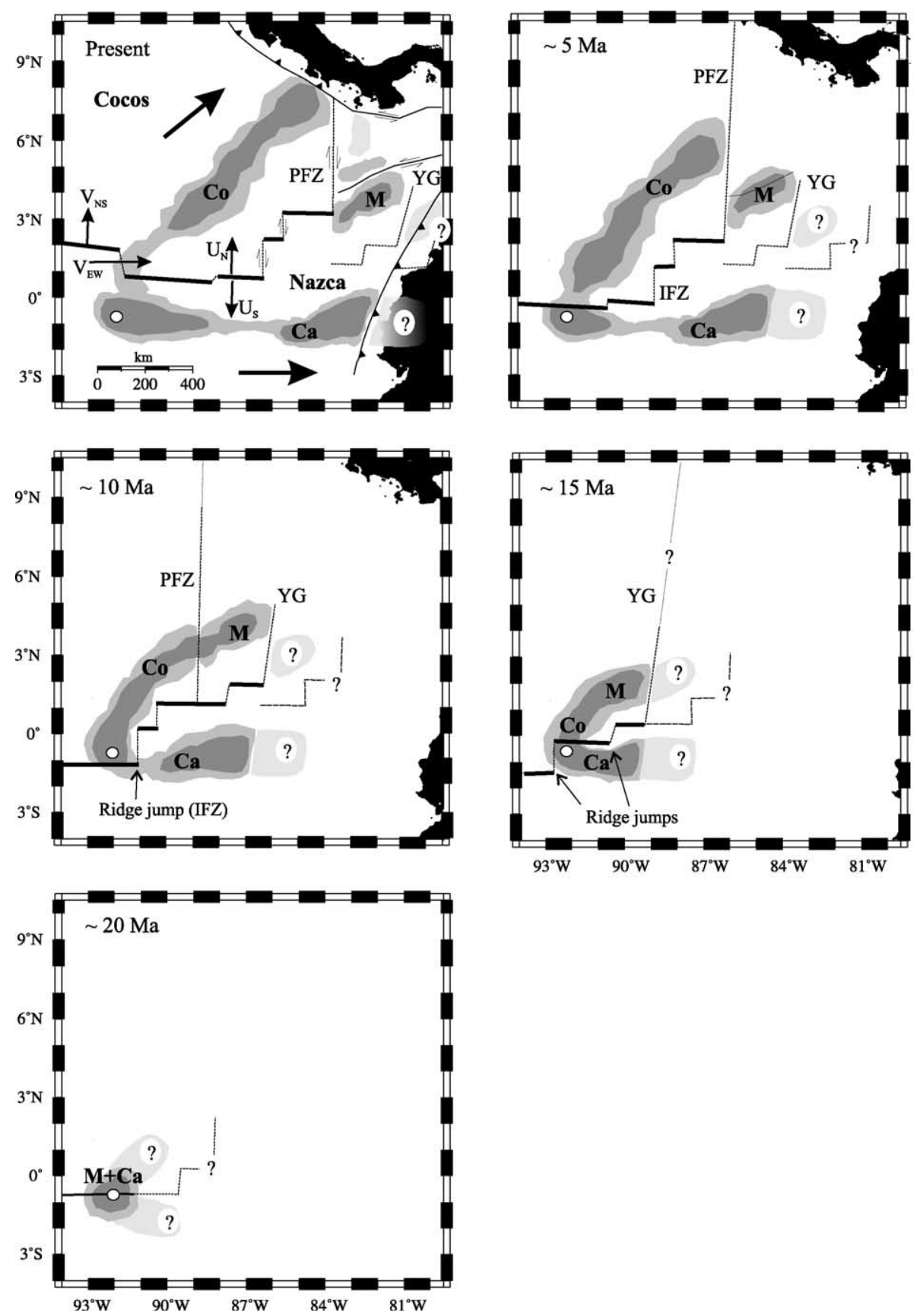

Fig. 4. Cartoon of the GVP tectonic evolution during the last $\sim 20$ m.y. based on the results obtained in this work. Thin arrows in panel a indicate the trend of oceanic spreading along the CNSC ( $U_{\mathrm{N}}$ and $U_{\mathrm{S}}$ ), the migration of the CNSC with respect to the hotspot $\left(V_{\mathrm{NS}}\right)$, and the E-W motion of the GVP relative to the stable South American craton, resulting from the oceanic spreading in the East Pacific Rise $\left(V_{\mathrm{EW}}\right)$. Thick arrows correspond to the aggregate of these three components (the motion of Cocos and Nazca plates relative to South America), which is outlined by the trends of Cocos and Carnegie ridges. The motion of the continents with respect to the GHS has been reconstructed assuming $<10 \mathrm{~km} / \mathrm{m} . \mathrm{y}$. E-W convergence for South America and NE-SW convergence for Central America during the last 20 m.y. [60]. PFZ: Panama fracture zone, IFZ: Inca fracture zone, YG: Yaquina graben, Ca: Carnegie Ridge, Co: Cocos Ridge, M: Malpelo Ridge. 
land, maximum crustal thickness is $30-35 \mathrm{~km}$, whereas normal thickness of crust generated at the Reykjanes ridge is $\sim 7 \mathrm{~km}$ [55]. The full spreading rate based on the model NUVEL-1A is $19 \pm 2 \mathrm{~km} / \mathrm{m} . \mathrm{y}$. [51], and the along-axis width of the plume influence, derived from the gradient of bathymetric and $\mathrm{Sr}$ isotopes concentration anomalies along the ridge, is $\sim 1200 \mathrm{~km}[56,57]$. This gives an along-axis excess melt flux for the Icelandic hotspot, $Q_{\mathrm{I}}=9.2 \pm 6.7 \mathrm{~m}^{3} / \mathrm{s}$, which is similar to that estimated for the GHS at $\sim 20$ Ma. This value is about $20 \%$ larger than that previously estimated by Phipps Morgan [52], but he just considered the excess of melt production immediately beneath the island platform and not along the Reykjanes ridge axis. Thus, as previously noted by Canales et al. [44], the thicker crust and the wider along-axis dispersal of plume material observed at the Reykjanes ridge are mostly compensated by the three-fold increase of the spreading rate along the CNSC.

\section{Tectonic evolution of the GVP}

In this section we show a plausible tectonic scenario for the GVP evolution from $20 \mathrm{Ma}$ to present day based on the results described in the previous section (Fig. 4). Most tectonic reconstructions suggest that the GHS began interacting with the CNSC at $\sim 23 \mathrm{Ma}[32,33,35]$. The magnetic anomalies of the oldest seafloor created at the CNSC indicate that between $\sim 23 \mathrm{Ma}$ and $\sim 20 \mathrm{Ma}$ the spreading center was orientated $\sim \mathrm{N} 45^{\circ} \mathrm{E}$, and its full spreading rate was significantly higher than that observed at present day (e.g. [37]). At 19-20 Ma, a major ridge jump reshaped its geometry, changing also the ridge orientation to $\sim \mathrm{N} 75^{\circ} \mathrm{E}$ and diminishing the spreading rate. In the previous section we showed that the GHS was approximately ridge-centered at this time. The interaction between the hotspot and the spreading center produced a thick oceanic plateau centered on the CNSC, similar to Iceland today (Fig. 4). Subsequently, the northern (Malpelo) and southern (Carnegie) segments of the plateau are split apart by seafloor spreading along the CNSC. Malpelo and easternmost Carnegie are thus the oldest aseismic ridge segments resulting from the GHS-CNSC interaction which are currently preserved within the GVP. At $\sim 20 \mathrm{Ma}$, the CNSC was already migrating to the north with respect to the GHS, with a velocity slightly lower than the half-spreading rate. The combination of CNSC migration, N-S spreading along the CNSC, and E-W spreading along the East Pacific Rise, resulted in the SW-NE motion of the Cocos plate and the E-W motion of the Nazca plate, as outlined by the trends of Cocos and Carnegie.

The northward migration of the CNSC was compensated by a series of major southward ridge jumps between $\sim 19.5 \mathrm{Ma}$ and $\sim 14.5 \mathrm{Ma}$, and consequently the active spreading center was staying near the GHS $(<50 \mathrm{~km})$ during this period of time. The last ridge jump (at $\sim 14.5 \mathrm{Ma}$ ), which probably corresponds to the Inca fracture zone (IFZ), reshaped the CNSC into its present configuration (Fig. 4). Barckhausen et al. [35] suggested that the GHS was the driving force producing southward ridge jumps and resulting in an asymmetric crustal accretion. Nevertheless, no major ridge jumps occurred since 14.5 m.y., which is not in agreement with ridge jumps only related to the influence of the presence of the GHS. Alternatively, we suggest that ridge jumps could also reflect a global tectonic reorganization related to differential forces between the north-eastward subducting Cocos plate and the eastward subducting Nazca plate, and thus they are not only related with the GHS.

At $\sim 12 \mathrm{Ma}$, the IFZ passed over the GHS from west to east, locating the hotspot beneath the Cocos plate far away from the spreading center $(\sim 150 \mathrm{~km})$. After that, the CNSC kept migrating northward, towards the GHS.

At about $9 \mathrm{Ma}$, the subduction of the eastern part of the Cocos plate beneath Middle America probably blocked, leading to the opening of the PFZ. West of it, the subduction of the Cocos plate and the seafloor spreading at the CNSC kept on, whereas the eastern segment was incorporated to the Nazca plate after the cessation of the seafloor spreading and of the northward migration of the CNSC (Fig. 4). This produced a differential motion along the dextral strike-slip PFZ which resulted in a southward drift of the 
Malpelo Ridge relative to the Cocos Ridge. South of the spreading center the PFZ continued as a less active transform fault because most of the southward seafloor spreading was compensated by the northward migration of the CNSC (Fig. 4). The small difference between both motions generated the shift observed along the northern flank of Carnegie Ridge at $\sim 83^{\circ} \mathrm{W}$. The CNSC moved toward the GHS between $\sim 12 \mathrm{Ma}$ and $\sim 7.5 \mathrm{Ma}$. At about this time, the CNSC passed over the GHS, and from then to now it has been moving away from the GHS to reach the location observed today (Fig. 4).

The subduction of the Cocos Ridge beneath Middle America is therefore very recent, starting probably after $\sim 2 \mathrm{Ma}$. The ridge fragments originated at the CNSC between $\sim 23 \mathrm{Ma}$ and 20 $\mathrm{Ma}$, if they once existed, should have eventually subducted beneath the South American Margin, between $0^{\circ}$ and $2^{\circ} \mathrm{S}$ (the possible continuation of the Carnegie Ridge), and between $2^{\circ} \mathrm{N}$ and $4^{\circ} \mathrm{N}$ (a block similar to the Malpelo Ridge) (Fig. 4). This would imply that the Yaquina graben once played a role similar to that of the PFZ (Fig. 4).

\section{Conclusions}

The joint interpretation of crustal thickness determined along the present-day axis of the CNSC and across the different aseismic ridges allows us to constrain the relative motion of the CNSC with respect to the GHS and, in turn, the tectonic evolution of the GVP during the last $\sim 20$ m.y. Our estimations are only approximate and depend strongly on several assumptions. Nevertheless, the remarkable agreement between our results and those obtained in a number of previous works using independent geophysical data and methods suggests that our approach is valid and suitable to place first-order constraints on the geodynamic evolution of the GVP.

The main conclusions of this study are the following:

1. The CNSC has been moving northwards with respect to the GHS at a mean rate of $26 \pm 4$ $\mathrm{km} / \mathrm{m}$.y. from $\sim 20 \mathrm{Ma}$ to present.

2. The GHS was ridge-centered at $\sim 20 \mathrm{Ma}$ and remained in the vicinity of the spreading center between $\sim 20 \mathrm{Ma}$ and $\sim 12 \mathrm{Ma}$.

3. Between $\sim 12 \mathrm{Ma}$ and $\sim 7.5 \mathrm{Ma}$ the GHS was located beneath the Cocos plate.

4. The CNSC passed over the GHS at $7.4 \pm 1.3$ $\mathrm{Ma}$, and thus the GHS has been located beneath the Nazca plate since this time.

5. The maximum potential excess volume flux of the Galapagos melt anomaly is $9.4 \pm 5.1 \mathrm{~m}^{3} / \mathrm{s}$, similar to that of the Icelandic one. The Hawaiian melt anomaly is, potentially, almost twice stronger than the Galapagos and Icelandic ones.

6. The PFZ opened at $8.9 \pm 1.6 \mathrm{Ma}$, triggered by the locking of the subduction of the easternmost Cocos plate beneath Middle America. Seafloor spreading and northward migration of the CNSC stopped east of the PFZ leading to the separation between the Cocos and Malpelo ridges.

7. The current separation between Malpelo and Cocos ridges, and the step observed in the northern flank of the Carnegie Ridge at $\sim 83^{\circ} \mathrm{W}$, are well explained if symmetric spreading with a mean full spreading rate of $62 \pm 19 \mathrm{~km} / \mathrm{m} . \mathrm{y}$. occurred along the CNSC the last $\sim 9$ m.y.

8. This model predicts that the Cocos plate is subducting beneath Middle America at a rate of $79 \pm 14 \mathrm{~km} / \mathrm{m}$.y. with a trend of $\mathrm{N} 44^{\circ} \pm$ $11^{\circ} \mathrm{E}$, in agreement with the results of recent GPS measurements.

\section{Acknowledgements}

We thank A. Bonneville and J. Phipps Morgan for their constructive reviews, which helped to improve substantially the original manuscript. V. Sallarès was supported by a Marie Curie Fellowship (contract HPMF-CT-1999-0039) during the time this work was conducted. The study was also supported by Institut de Recherche pour le Développement (IRD). We acknowledge the captain of the R/V Sonne, Henning Pepenhagen, the ship's crew, and all the scientific staff that participated in the PAGANINI-1999 and SALIERI2001 seismic experiments.[VC] 


\section{References}

[1] R.S. White, D. McKenzie, Magmatism at rift zones: The generation of volcanic continental margins and flood basalts, J. Geophys. Res. 94 (1989) 7685-7794.

[2] J.T. Wilson, A possible origin of the Hawaiian Islands, Can. J. Phys. 41 (1963) 863-870.

[3] W.J. Morgan, Convection plumes in the lower mantle, Nature 230 (1971) 42-43.

[4] M.A. Richards, R.A. Duncan, V.E. Courtillot, Flood basalts and hotspot tracks: plume heads and tails, Science 246 (1991) 103-107.

[5] J. Korenaga, W.S. Holbrook, G.M. Kent, P.B. Kelemen, R.S. Detrick, H.-C. Larsen, J.R. Hopper, T. Dahl-Jensen, Crustal structure of the southeast Greenland margin from joint refraction and reflection seismic tomography, J. Geophys. Res. 105 (2000) 21591-21614.

[6] J. Maclennan, D. McKenzie, K. Gronvold, Plume-driven upwelling under central Iceland, Earth Planet. Sci. Lett. 194 (2001) 67-82.

[7] J. Korenaga, P.B. Kelemen, Major element heterogeneity in the mantle source of the North Atlantic igneous province, Earth Planet. Sci. Lett. 184 (2000) 251-268.

[8] S.T. Crough, Hotspot swells, Annu. Rev. Earth Planet. Sci. 11 (1983) 163-193.

[9] N.H. Sleep, Hotspots and mantle plumes - some phenomenology, J. Geophys. Res. 95 (1990) 6715-6736.

[10] M.K. McNutt, A. Bonneville, A shallow, chemical origin, for the Marquesas swell, Geochem. Geophys. Geosyst. 1 (2000).

[11] J. PhippsMorgan, W.J. Morgan, E. Price, Hotspot melting generates both hotspot volcanism and a hotspot swell?, J. Geophys. Res. 100 (1995) 8045-8062.

[12] R.C. Courtney, R.S. White, Anomalous heat flow and geoid across the Cape Verde Rise: evidence for dynamic support from a thermal plume in the mantle, Geophys. J. Astron. Soc. 87 (1986) 815-867.

[13] E.R. Oxburgh, E.M. Parmentier, Compositional and density stratification in oceanic lithosphere - causes and consequences, J. Geol. Soc. Lond. 133 (1977) 343-355.

[14] P. Olson, Hot spots, swells, and mantle plumes, in: M.P. Ryan (Ed.), Magma Transport and Storage, John Wiley, New York, 1990, pp. 33-51.

[15] D. McKenzie, M.J. Bickle, The volume and composition of melt generated by extension of the lithosphere, J. Petrol. 29 (1988) 625-679.

[16] R.S. White, D. McKenzie, R.K. O'Nions, Oceanic crustal thickness from seismic measurements and rare earth element inversions, J. Geophys. Res. 97 (1992) 19683-19715.

[17] R.S. White, D. McKenzie, Mantle plumes and flood basalts, J. Geophys. Res. 100 (1995) 17543-17585.

[18] J. Korenaga, P.B. Kelemen, W.S. Holbrook, Methods for resolving the origin of large igneous provinces from crustal seismology. J. Geophys. Res. 107 (2002) 2178, 10.1029/ 2001JB001030.

[19] A.B. Watts, U.S. tenBrink, P. Buhl, T.M. Brocher, A multichannel seismic study of lithospheric flexure across the Hawaiian-Emperor seamount chain, Nature 315 (1985) 105-111.

[20] D.W. Caress, M.K. McNutt, R.S. Detrick, J.C. Mutter, Seismic imaging of hotspot-related crustal underplating beneath the Marquesas Islands, Nature 373 (1995) 600 603.

[21] P. Charvis, S. Operto, Structure of the Cretaceous Kerguelen Volcanic Province (southern Indian Ocean) from wide-angle seismic data, J. Geodyn. 28 (1999) 51-71.

[22] P. Charvis, A. Laesanpura, J. Gallart, A. Hirn, J.-C. Lépine, B. deVoogd, T.A. Minshull, Y. Hello, B. Pontoise, Spatial distribution of hotspot material added to the lithosphere under La Réunion, from wide-angle seismic data, J. Geophys. Res. 104 (1999) 2875-2893.

[23] I. Grevemeyer, E.R. Flueh, C. Reichert, J. Bialas, D. Klaeschen, C. Kopp, Crustal architecture and deep structure of the Ninetyeast Ridge hotspot trail from active source ocean bottom seismology, Geophys. J. Int. 144 (2001) 1-22.

[24] S. Watson, D. McKenzie, Melt generation by plumes: a study of Hawaiian volcanism, J. Petrol. 32 (1991) 501537.

[25] P.R. Vogt, Asthenosphere motion recorded by the ocean floor south of Iceland, Earth Planet. Sci. Lett. 13 (1971) $153-160$.

[26] P.R. Vogt, Plumes, subaxial pipe flow, and topography along the mid-oceanic ridge, Earth. Planet. Sci. Lett. 29 (1976) 309-325.

[27] W.J. Morgan, Rodriguez, Darwin, Amsterdam, ..., A second type of hotspot island, J. Geophys. Res. 83 (1978) 5355-5360.

[28] J.-G. Schilling, Fluxes and excess temperatures of mantle plumes inferred from their interaction with migrating midoceanic ridges, Nature 352 (1991) 397-403.

[29] G. Ito, J. Lin, C.W. Gable, Interaction of mantle plumes and migrating mid-ocean ridges: Implications for the Galapagos plume-ridge system, J. Geophys. Res. 102 (1997) 15403-15417.

[30] J.-G. Schilling, Upper mantle heterogeneities and dynamics, Nature 314 (1985) 62-67.

[31] G. Ito, J. Lin, Oceanic spreading center hotspot interactions - constraints from along-isochron bathymetric and gravity anomalies, Geology 23 (1995) 657-660.

[32] R.N. Hey, Tectonic evolution of the Cocos-Nazca spreading center, Geol. Soc. Am. Bull. 88 (1977) 1404-1420.

[33] P. Lonsdale, K.D. Klitgord, Structure and tectonic history of the eastern Panama Basin, Geol. Soc. Am. Bull. 89 (1978) 981-999.

[34] G. Ito, J. Lin, Mantle temperature anomalies along the present and paleoaxes of the Galapagos Spreading Center as inferred from gravity analyses, J. Geophys. Res. 100 (1995) 3733-3745.

[35] U. Barckhausen, C.R. Ranero, R. vonHuene, S.C. Cande, H.A. Roeser, Revised tectonic boundaries in the Cocos plate off Costa Rica: Implications for the segmentation of the convergent margin and for plate tectonic models, J. Geophys. Res. 106 (2001) 19207-19220. 
[36] D.S. Wilson, R.N. Hey, History of rift propagation and magnetization intensity for the Cocos-Nazca spreading center, J. Geophys. Res. 100 (1995) 10041-10056.

[37] M. Meschede, U. Barckhausen, H.-U. Worm, Extinct spreading on the Cocos Ridge, Terra Nova 10 (1998) 211-216.

[38] J.T. Freymuller, J.N. Kellogg, V. Vega, Plate motions in the North-Andean region, J. Geophys. Res. 98 (1993) 21853-21863.

[39] J.N. Kellogg, V. Vega, Tectonic development of Panama, Costa Rica, and the Colombian Andes: Constraints from Global Positioning System geodetic studies and gravity, Geol. Soc. Am. Special Paper 295 (1995) 75-90.

[40] R. Trenkamp, J.N. Kellogg, J.T. Freymueller, H.P. Mora, Wide plate margin deformation, southern Central America and northwestern South America, CASA GPS observations, J. South Am. Sci. 15 (2002) 157-171.

[41] J. Bialas, E.R. Flüh, G. Bohrmann, Paganini Scientific Party, FS Sonne Cruise Report SO144/1 and 2, PAGANINI (San Diego, Caldera), GEOMAR, Kiel, 1999.

[42] B. Marcaillou, P. Charvis, J.-Y. Collot, E. Flueh, J. Bialas, Deep structure of the Malpelo Ridge (Colombia) from seismic and gravity modeling, XVI EGS General Assembly, Abstracts, Nice, 2001, p. 72.

[43] V. Sallarès, P. Charvis, E.R. Flueh, J. Bialas, Seismic structure of the Cocos and Malpelo volcanic ridges and implications for hotspot-ridge interaction, submitted to J. Geophys. Res. (2003).

[44] J.P. Canales, G. Ito, R.S. Detrick, J. Sinton, Crustal thickness along the western Galapagos Spreading Center and compensation of the Galapagos Swell, Earth Planet. Sci. Lett. 203 (2002) 311-327.

[45] D.R. Toomey, E.E. Hooft, R.S. Detrick, Crustal thickness variations and internal structure of the Galapagos Archipelago, EOS Trans. AGU 82 (47), Fall Meet. Suppl. Abstr. T42B-0939, 2001.

[46] E.R. Flüh, J. Bialas, P. Charvis, and the Salieri Scientific Party, Cruise report SO159 SALIERI, GEOMAR, Kiel, 2001.

[47] V. Sallarès, P. Charvis, E.R. Flueh, J. Bialas, C. Wahlter, Wide-angle seismic constraints on the evolution of Galapagos hotspot - Cocos-Nazca spreading center interaction, EGS XXVII General Assembly, EGS02-A-03145, 2002.

[48] W.D. Pennington, Subduction of the Eastern Panama Basin and seismotectonics of northwestern South America, J. Geophys. Res. 86 (1981) 10753-10770.
[49] R.A. Kolarsky, P. Mann, W. Montero, Island arc response to shallow subduction of the Cocos Ridge, Costa Rica, in: P. Mann (Ed.), Geologic and Tectonic Development of the Caribbean Plate Boundary in Southern Central America, Geol. Soc. Am. Special Paper 295, 1995, pp. 235-262.

[50] R. Werner, K. Hoernle, P. van den Bogaard, C.R. Ranero, R. Von Huene, D. Korich, A drowned 14-m.y.-old Galapagos archipelago off the coast of Costa Rica Implications for tectonic and evolutionary models, Geology 27 (1999) 499-502.

[51] C. DeMets, R.G. Gordon, D.F. Argus, S. Stein, Effect of recent revisions to the geomagnetic reversal time scale on estimates of current plate motions, Geophys. Res. Lett. 21 (1994) 2191-2194.

[52] J. Phipps Morgan, The generation of a compositional lithosphere by mid-ocean ridge melting and its effect on subsequent off-axis hotspot upwelling and melting, Earth Planet. Sci. Lett. 146 (1997) 213-232.

[53] D.A. Lindwall, A two dimensional seismic investigation of crustal structure under the Hawaiian islands near Oahu and Kauai, J. Geophys. Res. 93 (1988) 12107-12122.

[54] A.E. Gripp, R.G. Gordon, Current plate velocities relative to the hotspots incorporating the NUVEL-1 global plate motion model, Geophys. Res. Lett. 17 (1990) 1109 1112.

[55] J.R. Smallwood, R.S. White, T.A. Minshull, Seafloor spreading in the presence of the Iceland plume: the structure of the Reykjanes Ridge at $61^{\circ} 40^{\prime} \mathrm{N}$, J. Geol. Soc. London 152 (1995) 1023-1029.

[56] G. Ito, J. Lin, C.W. Gable, Dynamics of mantle flow and melting at a ridge-centered hotspot: Iceland and the Mid-Atlantic Ridge, Earth Planet. Sci. Lett. 144 (1996) 53-74.

[57] J.-G. Schilling, Geochemical and isotopic variation along the Mid-Atlantic Ridge axis from $79^{\circ} \mathrm{N}$ to $0^{\circ} \mathrm{N}$, in: P.R. Vogt, B.E. Tucholke (Eds.), The Geology of North-America, GSA, Boulder, CO, 1986, pp. 137-156.

[58] R.D. Mueller, W.R. Roest, J.-Y. Royer, L.M. Gahagan, J.G. Sclater, A digital age map of the ocean floor, SIO Reference Series 93-30, Scripps Institution of Oceanography, 1996.

[59] B. Parsons, J.G. Sclater, An analysis of the variation of ocean floor bathymetry and heat flow with age, J. Geophys. Res. 82 (1977) 803-826.

[60] W.J. Morgan, Hotspot tracks and the early rifting of the Atlantic, Tectonophysics 94 (1983) 123-139. 